\title{
A pilot case-control study using a one health approach to evaluate behavioral, environmental, and occupational risk factors for chronic kidney disease of unknown etiology in Sri Lanka
}

Jesse Pry ( $\nabla$ jpry@wustl.edu )

Centre for Infectious Disease Research Zambia (CIDRZ) https://orcid.org/0000-0001-6312-4420

Wendi Jackson

University of California Davis

Ruwini Rupasinghe

University of California Davis

Guneratne Lishanthe

Renal Research Centre, District Hospital, Girandurokotte, Sri Lanka

\section{Zied Badurdeen}

University of Peradeniya Faculty of Medicine

\section{Tilak Abeysekara}

University of Peradeniya Faculty of Medicine

Rohana Chandrajith

University of Peradeniya Faculty of Science

Woutrina Smith

University of California Davis

\section{Saumya Wickramasinghe}

University of Peradeniya Faculty of Veterinary Medicine and Animal Science

Research article

Keywords: chronic kidney disease, Sri Lanka, risk factors, one health approach

Posted Date: December 10th, 2019

DOI: https://doi.org/10.21203/rs.2.18458/v1

License: (9) (i) This work is licensed under a Creative Commons Attribution 4.0 International License.

Read Full License 
Version of Record: A version of this preprint was published at One Health Outlook on February 23rd, 2021. See the published version at https://doi.org/10.1186/s42522-020-00034-3. 


\section{Abstract}

Chronic kidney disease of unknown etiology (CKDu) was first recognized in Sri Lanka in the early 1990s, and since then it has reached epidemic levels in the North Central Province of the country. The prevalence of CKDu is reportedly highest among communities that engage in chena and paddy farming, which is most often practiced in the dry zone including the North Central and East Central Provinces of Sri Lanka. Previous studies have suggested varied hypotheses for the etiology of CKDu; however, there is not yet a consensus on the primary risk factors, possibly due to disparate study designs, sample populations, and methodologies. The goal of this pilot case-control study was to evaluate the relationships between key demographic, cultural, and occupational variables as risk factors for $\mathrm{CKDu}$, with a primary interest in pesticide exposure both occupationally and through its potential use as an ingredient in brewed kasippu alcohol. A total of 56 CKDu cases and 54 control individuals were surveyed using a proctored, selfreported questionnaire. Occupational pesticide exposure and alcohol consumption were not found to be significant risk factors for CKDu. However, a statistically significant association with CKDu was observed with chewing betel (OR: $6.11,95 \% \mathrm{Cl}: 1.93,19.35)$, age (OR: 1.07, 95\% Cl: 1.02, 1.13), owning a pet dog (OR: 3.74, 95\% Cl: 1.38, 10.11), water treatment (OR: 3.68, 95\% Cl: 1.09, 12.43) and pests in the house (OR: $5.81,95 \% \mathrm{Cl}: 1.56,21.60)$. The findings of this study suggest future research should focus on practices associated with chewing betel, potential animal interactions including pests in the home and pets, and risk factors associated with water.

\section{Introduction}

There has been a notable increase in the recognized incidence of chronic kidney disease (CKD) around the world [1]. Kidney disease has moved from 27th most common cause of death in 1990, to 18th in 2010 and has come to be considered a global public health problem causing high morbidity, mortality, and financial burden [2-4]. Global prevalence of CKD is estimated to range between $8 \%$ and $16 \%$, and differs substantially across developed and developing countries $[3,5]$. Although diabetes mellitus and hypertension remain the leading causes of CKD, in recent years a different form of CKD has reached epidemic levels, devastating rural communities in the dry zone of Sri Lanka [6,7]. The recognition of endemic CKD in the dry zone in the 1990s coincided with the development of the rural healthcare system, which improved access to clinics by affected individuals. Since that time, the dry zone has seen a disproportionate increase in cases of CKD compared to the rest of the country [8]. Existing studies describe the majority of these CKD patients as not having hypertension or diabetes mellitus, two of the major risk factors for CKD. It has therefore, been defined as a distinct condition: CKD of unknown or uncertain etiology (CKDu). Similar chronic kidney disease hotspots have been recognized among farmers in Central America (Nicaragua and El Salvador) and South Asia $[9,10]$.

Approximately 2.5 million people live in the subset of Sri Lankan provinces where CKDu is most common $[11,12]$. Cases of this disease predominate in the Medawachchiya, Wilgamuwa, Nikawewa, and Girandurukotte regions of the dry zone. Studies have shown the highest prevalence of CKDu among 30- 
60 year old men engaged in chena or rice farming, and estimate a total of 20,000 (approximately $0.8 \%$ population) affected in the North Central Province $[8,13]$.

The epidemic of CKDu in the dry zone is burdening the rural healthcare system and impacting agricultural productivity due to a reduction in the available labor force when CKDu patients are too ill to work [14-16]. Due to the irreversible and progressive nature of CKD, most patients require long-term dialysis since renal transplants are not commonly available. For these reasons, there is a need to determine the risk factors associated with CKDu to control and attenuate the incidence of new CKDu cases. A growing body of evidence suggests that CKDu is multi-factorial, making it difficult to identify individual risk factors and potential interactions involved in pathogenesis $[7,12,17-20]$. Recently, various heavy metal agents such as cadmium, arsenic agrochemicals, aluminum, and fluoride, as well as infectious diseases such as leptospirosis have been considered for association with CKDu [21-26].

Collaboration between researchers at the University of Peradeniya in Sri Lanka, the University of California, Davis (UCD) in the United States, and Sri Lankan stakeholders in CKDu-endemic areas were involved in this pilot study. The driving hypothesis for this study is that alcohol consumption and/or pesticide exposure are associated with CKDu as a health outcome. In addition, it is recognized that relationships between key demographic, cultural, and occupational variables may play a role in CKDu health outcomes [27-31].

\section{Materials And Methods}

A pilot case-control study was conducted in Sri Lanka from July-October 2015. The study population was comprised of individuals (cases and controls) who resided in the North Central Province (NCP) or Uva Province (UP) and sought medical care at Girandurukotte district hospital (UP) or Medawachchiya clinic (NCP). The population in both the NCP and UP is approximately 1.2 million, with women making up the slight majority (51\%) [13]. The majority of people in both provinces are Sinhalese-speaking and resides in the rural sector where they engage in farming (chena, rice). The NCP has the highest recorded prevalence of CKDu cases in Sri Lanka and is located in the country's dry zone. Uva Province is in the intermediate zone adjacent to the dry zone, with a lower prevalence of CKDu cases compared to the NCP.

In order to test the hypothesis that there is a relationship between alcohol consumption and CKDu diagnosis, and pesticide exposure and CKDu, in endemic areas of Sri Lanka, a questionnaire survey was developed [See Additional File 1]. The survey tool encompassed a wide range of exposures to capture potential unknown confounders, including exposures suggested by local CKDu working groups at the University of Peradeniya. Individuals meeting the CKDu case definitions as well as a comparison (control) population from the same endemic region were invited for participation in the survey.

\section{Case Definition}

Individuals diagnosed with definite or probable CKDu by a nephrologist at the Girandurukotte regional hospital or Medawachchiya renal clinic made up the population from which study cases were selected. 
An individual was considered a definite CKDu case if creatinine levels were elevated and subsequent renal biopsy the finding was predominant tubular interstitial nephritis. A probable CKDu case was defined as persistent renal dysfunction for more than 3 months after excluding known causes including hypertension, diabetes mellitus, any other known renal diseases. Controls were chosen based on negative results for CKDu from hospital or population screening records.

\section{Recruitment}

All controls were recruited using CKDu screening results within the past three years. These CKDu negative were invited via post (hard copy letter) to return to the healthcare facility associated with the previous screening to take part in a survey. Participation in the survey was optional. All cases were recruited from Girandurukotte regional hospital or Medawachchiya renal clinic.

\section{Sample Size Calculation}

The total sample size calculated for this pilot case-control study was 110 , comprising $1: 1$ cases to controls. The target sample size of 110 individuals was calculated based on a power of $80 \%(\beta=0.2)$, $95 \%$ confidence $(a=0.05)$, and a minimum effect size of 3.0 . This relatively large effect size was considered in the exploratory study in order to identify preliminary exposures strongly associated with the outcome. An estimate of $26 \%$ was used for any reported alcohol consumption among controls for the sample size calculation [32, 33].

\section{Survey Design}

Survey questions were designed by the research team in consultation with the resource personnel at the Centre for Research, Education, and Training on Kidney Diseases (CERTkID) in Sri Lanka prior to IRB approval, survey training, and interviews. The survey consisted of 138 questions structured as binary, categorical, ordinal, and open-ended across six categories: 1) agricultural information; 2) animal exposure; 3) water and nutrition; 4) alcohol consumption; 5) respondent demographics; and 6) family and past medical history.

The agricultural information section included questions related to farming practices and agrochemical usage. Information on ownership and health of livestock and pets, presence of pest animals and wild life were collected in section two of the survey. In the water and nutrition information section, sources for drinking, cooking, and bathing water were assessed, along with participant practices regarding water treatment prior to use. The alcohol consumption information section contained questions on type of alcohol consumed, betel chewing and smoking status. Alcohol consumption was assessed in two ways: a binary question was asked first on whether the participant had ever consumed alcohol (if yes, what type and frequency) and second, whether the participant believed that alcohol was a problem in their village. The respondent demographics section contained questions pertaining to level of education and family income. To assess a potential genetic component of CKDu, participants were asked whether their spouses were close blood relatives and family history of CKDu, hypertension, and diabetes mellitus was 
also recorded. Detailed survey and explanation of survey components are given in Supplementary information.

Survey data were collected by 12 trained graduate students associated with the University of Peradeniya. In addition, investigators were present at each site during data collection, allowing surveyors the opportunity for clarification as needed in real-time as interviews were conducted. Cases and controls participated voluntarily and surveys were administered verbally in the mother tongue of the participants (Sinhala) after obtaining consent (see Supplementary Information for the English version of the consent form and survey questions). Survey question responses were recorded on paper copies of the questionnaire by the surveyor. Each interview took approximately one hour to complete.

The research protocol was designed according to the guidelines of the International Compilation of Human Research Standards (2015 edition) and approved by the University of California, Davis Institutional Review Board (\#762486-2). Written consent of all study participants was obtained by signature or thumbprint after survey enumerators verbally read the consent statement in the appropriate language. The consent form was translated in both Sinhala and Tamil. The majority of survey interviews took place at medical clinics specializing in renal disease.

\section{Statistical Analyses}

Logistic regression was used to evaluate risk factors for CKDu case status. Potential risk factor association with the outcome of interest was assessed and a cutoff p-value $\leq 0.20$ was used to restrict consideration for the final model. Pearson's correlation coefficient was used to identify covariate correlation at $-0.5 \leq \geq 0.5$. Data analysis was completed using Stata IC 14 (StataCorp LP, College Station, TX USA). Multiple logistic regression analyses were performed using backwards stepwise selection to model the risk factors associated with the CKDu disease outcome of interest. Adjusted analysis was done to control for possible confounding by measured covariates. Statistical significance was assessed at the $=0.05$. Mapping was completed using QGIS v2.18 (Free Software Foundation, Inc. Boston, MA 02110-1301 USA) with GADM administrative boundary layers v2.8 (accessed November 2015).

\section{Results}

A total of 110 participants were included in the analysis; 56 met the case definition and 54 satisfied control criteria (Table S1). All participants resided in the CKDu endemic regions in Girandurukotte and Medawachchiya districts in Sri Lanka at the time of diagnosis. Participants had a mean age of 52.6 years (range $=25-80)$; there was a slight majority of males $(60 \%)$ to females $(40 \%)$. Most participants reported to be married, with about half reporting being married to a spouse that was a close blood relative and slightly over half reporting a family member having been diagnosed with CKDu 
(Table S1). Of the 110 study participants, half reported consuming any type of alcohol and the majority reported using some type of pesticide in their daily lives (insecticide, herbicide, in-home pesticide and/or fungicide) (Table S1).

The majority of participants (74) were residing in the Uva Province. Twenty-two participants resided in the North Central Province, five in the Eastern Province, two in the Central Province and one resided in the Northwestern Province. There were 8 (7.3\%) individuals for whom reliable current residence information was not available due to survey legibility and standardization complications. Data regarding province in which the participant was born were collected (Figure 1). No participants reported birth outside of Sri Lanka.

Figure 1. Map of Sri Lanka by district indicating participant's birth district

After bivariate and correlational analyses, smoking unfiltered cigarettes and smoking cannabis were found to be highly correlated (correlation coefficient $=0.5141>0.5$ threshold). Smoking unfiltered cigarettes was dropped from model consideration given a bivariate $p$-value higher than that of smoking cannabis ( $p$-value $=0.186$ and 0.112 , respectively).

Sources of drinking water were surveyed and 'dug well' was the most common source $(90.9 \%)$ of drinking/cooking water, with 'rainwater collection containers' being the second most common source. Drinking water was reported to be treated with routine methods such as boiling or filtering, or traditional methods such as placing igini (strychnos potatorum) seeds in the water source/well [34]. A subset of key population characteristics is reported in Table 1.

\section{Table 1: Study Population Characteristics by Case-Control Status}




\begin{tabular}{|c|c|c|c|c|}
\hline Factor & Level & Control & Case & $p$-value \\
\hline$N$ & & 54 & 56 & \\
\hline Age, mean (SD)* & & 49.5 (11.7) & $57.5(9.6)$ & $<0.001$ \\
\hline \multirow[t]{2}{*}{ Gender* } & Female & $27(51)$ & $16(29)$ & 0.017 \\
\hline & Male & $26(49)$ & $40(71)$ & \\
\hline \multirow[t]{2}{*}{ Farming as Occupation* } & No & $14(28)$ & $3(6)$ & 0.002 \\
\hline & Yes & $36(72)$ & $51(94)$ & \\
\hline \multirow[t]{2}{*}{ Drinking Water Source } & Dug Well & $48(89)$ & $52(93)$ & 0.47 \\
\hline & Rain Water & $6(11)$ & $5(9)$ & 0.7 \\
\hline Treat Drinking Water & Drinking & $34(63)$ & $41(75)$ & 0.19 \\
\hline Keep Livestock & Livestock & $17(31)$ & $19(34)$ & 0.78 \\
\hline \multirow[t]{2}{*}{ Smoking Status } & Tobacco & $8(15)$ & $14(25)$ & 0.18 \\
\hline & Cannabis & $2(4)$ & $7(12)$ & 0.092 \\
\hline Chew Betel* & Betel & $22(41)$ & $40(71)$ & 0.001 \\
\hline \multirow[t]{4}{*}{ Alcohol a Problem in Village } & Not a Problem & $13(27)$ & $11(21)$ & 0.85 \\
\hline & Minor Problem & $17(35)$ & $20(38)$ & \\
\hline & Moderate Problem & $10(20)$ & $9(17)$ & \\
\hline & Major Problem & $9(18)$ & $12(23)$ & \\
\hline \multirow[t]{4}{*}{ Alcohol Consumption } & Any Alcohol & $22(41)$ & $33(59)$ & 0.056 \\
\hline & Arrack & $19(35)$ & $27(48)$ & 0.17 \\
\hline & Beer & $14(26)$ & $16(29)$ & 0.76 \\
\hline & Kasippu & $13(24)$ & $18(32)$ & 0.35 \\
\hline \multirow[t]{4}{*}{ Pesticide Use* } & Any & $42(78)$ & $52(93)$ & 0.025 \\
\hline & Fungicide & $21(44)$ & $29(55)$ & 0.27 \\
\hline & Herbicide & $41(76)$ & $51(91)$ & 0.032 \\
\hline & Insecticide & $42(78)$ & $44(79)$ & 0.92 \\
\hline
\end{tabular}

*Significance attributed as $p$-value $<0.05$ 
There is a significant difference between age, gender, occupation, chewing betel, pesticide use at the $95 \%$ confidence level. The cases were older, on average, by eight years than the control group with a gender imbalance finding males more often among the cases compared to controls. Cases cited farming as an occupation more often than controls (22\% higher among cases), reported chewing betel ( $30 \%$ higher among cases), and used pesticides more often, specifically herbicide, (15\% higher among cases).

Two multivariable models were constructed, an exposure of interest model and an exploratory model. The exposure of interest model forced inclusion of variables concerning alcohol consumption and pesticide exposure, as neither exposure of interest was found to be significantly associated with CKDu in bivariate analysis (Table 2). The final exposure of interest model included four variables and excluded one variable compared to the stepwise method used for the exploratory model (Table 3). The exploratory model (Table 3) included only risk factors significantly associated with CKDu status $(P<0.05)$. The primary exposures of interest (alcohol consumption and pesticide exposure) were not found to be significant using a backward stepwise selection process. However, age - considered as a continuous variable (OR: 1.08, 95\% Cl 1.02, 1.13), chewing betel (OR 4.01, 95\% $\mathrm{Cl} 1.49,10.81)$, keeping a pet dog (OR: $4.21,95 \% \mathrm{Cl} 1.55,11.48$ ), and reporting pests in the home (OR: 3.96, 95\% Cl 1.21, 12.93) were significantly associated with CKDu case status.

\section{Table 2. Factors Associated with CKDu including Pesticide and Alcohol Consumption in Sri Lanka}




\begin{tabular}{l|cccc}
\hline Factor & Odds Ratio & P-Value & 95\% Confidence Interval \\
\hline Age* & 1.12 & $<0.01$ & 1.04 & 1.21 \\
Sex: Male & 6.19 & 0.07 & 0.73 & 44.06 \\
Chew betel & 3.57 & 0.08 & 0.86 & 14.84 \\
Pet dog* & 4.41 & 0.03 & 1.19 & 16.27 \\
Pests in-home* & 8.19 & 0.02 & 1.45 & 46.18 \\
Consume Arrack & 0.64 & 0.62 & 0.11 & 3.86 \\
Consume Beer & 1.15 & 0.88 & 0.18 & 7.34 \\
Consume Kasippu & 0.26 & 0.23 & 0.03 & 2.39 \\
Fungicide & 1.45 & 0.57 & 0.41 & 5.17 \\
Herbicide & 1.00 & 1.00 & - & - \\
In-home pesticide & 0.82 & 0.79 & 0.34 & 4.97 \\
Insecticide & 1.00 & 1.00 & - & - \\
\hline
\end{tabular}

Note: Exposures of interest kept in model despite non-significant $p$-value

*Significance attributed as p-value $<0.05$

Table 3. Factors Associated with CKDu in Sri Lanka

\begin{tabular}{l|cccc}
\hline Factor & Odds Ratio & P-Value & 95\% Confidence Interval \\
\hline Chew betel* & 5.95 & 0.002 & 1.878 & 18.856 \\
Pet dog* & 3.515 & 0.012 & 1.312 & 9.42 \\
Treat water* $^{*}$ & 3.944 & 0.026 & 1.175 & 13.236 \\
Pests in-home* $^{*}$ & 5.708 & 0.009 & 1.538 & 21.182 \\
Age* $^{*}$ & 1.078 & 0.003 & 1.025 & 1.133 \\
\hline
\end{tabular}

*Significance attributed as $p$-value $<0.05$ 
Bivariate analyses for specific types of pesticides and fertilizers used are detailed in Table 4. Before adjustment for age, gender, occupation, and alcohol consumption, usage of a fertilizer (muriate of potash) and an herbicide (glyphosate) were significantly associated with confirmed CKDu cases. However, after adjustment, none of the fertilizers, insecticides, or herbicides reported were found to be significantly associated with the outcome of interest, and so were not included in multivariable models (Table 4).

Table 4. Agrochemical Association with CKDu - Crude and Adjusted Odds Ratios

\begin{tabular}{|c|c|c|c|c|}
\hline Factor & $\begin{array}{c}\text { Control } \\
(\mathrm{N}=54) \\
\mathrm{n}(\%)\end{array}$ & $\begin{array}{c}\text { Case } \\
(\mathrm{N}=56) \\
\mathrm{n}(\%)\end{array}$ & $\begin{array}{l}\text { Crude Odds Ratio (95\% } \\
\qquad \mathrm{Cl})\end{array}$ & $\begin{array}{l}\text { Adjusted Odds Ratio } \\
\qquad(95 \% \mathrm{Cl})\end{array}$ \\
\hline \multicolumn{5}{|l|}{ Fertilizer } \\
\hline Urea & $38(70 \%)$ & $47(84 \%)$ & $2.20(0.9,5.5)$ & $0.92(0.3,3.2)$ \\
\hline Muriate of Potash* & $1(2 \%)$ & $0(0 \%)$ & $3.15(1.4,7.4)$ & $1.86(0.7,5.1)$ \\
\hline Triple Super & $11(20 \%)$ & $21(38 \%)$ & $2.35(1.0,5.5)$ & $1.84(0.7,5.2)$ \\
\hline \multicolumn{5}{|l|}{ Phosphate } \\
\hline Mud/Manure & $11(20 \%)$ & $5(9 \%)$ & $0.38(0.1,1.2)$ & $0.41(0.1,1.5)$ \\
\hline \multicolumn{5}{|l|}{ Insecticide } \\
\hline Carbosulfan & $5(9 \%)$ & $3(5 \%)$ & $0.55(0.13,2.44)$ & $0.48(0.1,2.5)$ \\
\hline Carbofuran & $4(7 \%)$ & $4(7 \%)$ & $0.96(0.23,4.06)$ & $0.47(0.1,2.4)$ \\
\hline Curateer & $7(13 \%)$ & $6(11 \%)$ & $0.81(0.25,2.57)$ & $0.74(0.2,2.8)$ \\
\hline \multicolumn{5}{|l|}{ Herbicide } \\
\hline Glyphosate* & 19 (35\%) & $32(57 \%)$ & $2.46(1.14,5.30)$ & $1.09(0.4,2.8)$ \\
\hline MCPA & $24(44 \%)$ & $28(50 \%)$ & $1.25(0.59,2.65)$ & $0.92(0.4,2.3)$ \\
\hline DPA & $11(20 \%)$ & $17(30 \%)$ & $1.70(0.71,4.08)$ & $0.88(0.3,2.5)$ \\
\hline Metamifop & $8(15 \%)$ & $8(14 \%)$ & $0.96(0.33,2.77)$ & $1.39(0.4,4.9)$ \\
\hline
\end{tabular}

* $p \leq 0.05$; Adjusted by age, gender, farming occupation and alcohol consumption 


\section{Figure 2: Proportional Venn Diagrams Representing Reported Alcohol Type Consumed by Case-Control Status}

Figure 2 illustrates the difference between cases (A) and control (B) by type of alcohol reportedly consumed. Cases were more likely to report drinking. The overlap between all three types of alcohol indicates that if one consumes alcohol it is common to drink all three types surveyed. Arrack was the most commonly reported alcohol consumed across cases and controls. Overall reported alcohol consumption was observed among $2.3 \%$ of women, while $81.8 \%$ of men reported drinking alcohol (twosided Fisher's exact: <0.001).

\section{Discussion}

There was no significant association detected between CKDu and pesticide exposure nor alcohol consumption. However, there were significant associations identified for chewing betel, owning a pet dog, treatment of drinking water, reporting pests in the home, and age. These significant exposures provide insight into previously unconsidered routes and mechanism for CKDu in addition to potential guidance on how to reduce odds of CKDu diagnosis. Chewing betel could be a risk directly or indirectly through contamination of the traditional chew ingredients or through handling and/or preparation of the betel chew. The association between report of a pet dog could suggest a zoonotic pathway and pests in the home could indicate pest extermination agent risks or a disease reservoir. Treatment of drinking water, especially boiling, may contribute to consumption of aluminum with nephrotoxic consequences. The wide variety of associated exposures suggests that there may be multiple risk factors associated with $\mathrm{CKDu}$, which is consistent with results of previous studies $[35,36]$.

It is important to note that those cases reporting ever having been diagnosed with diabetes or hypertension were diagnosed after meeting the CKDu case definition. Prevalence of diabetes among controls was high (24.1\%) relative to the 2011 and 2030 national estimates of $7.8 \%$ and $9.1 \%$, respectively [37]. The questionnaire did not differentiate between type I or type II diabetes mellitus, limiting inferences about reasons for this discrepancy in prevalence. It is possible that changes in meal preparation (bivariate $\mathrm{OR}=1.6095 \% \mathrm{Cl} 0.74-3.44$ ) and/or food stuffs available in rural Sri Lanka also play a role in the increased prevalence of diabetes in this control sample. Conversely, diagnosis of hypertension is significantly higher (Fisher's exact $=0.002$ ) among the cases. However, this is common sequelae of chronic kidney disease [38-40]. 
Uses of a variety of agrochemicals are common throughout the farming dry zone regions and are often readily available through government subsidies. In our study, only herbicide use was shown to be significant in the bivariate analysis among all insecticide, fungicide, and in-home pesticide parameters. It is possible that exposure to pesticide occurs among those farmers reporting no use of pesticides on their crops through adjacent farm pesticide use in tandem with dynamic environmental factors, i.e. flooding, water source contamination, and winds.

The ingredients used in making kasippu, an illicit locally brewed alcohol, were of special interest in this study, due to prior hypothesis that pesticides are introduced in the brewing process. However, study participants who reported drinking kasippu most often purchased it from other villagers and either did not know the ingredients used or did not want to report drinking kasippu due to it being an illicit form of alcohol in Sri Lanka as well as the perceived cultural stigma for reporting use. Of those that did report drinking kasippu, some reported urea as an ingredient in kasippu production, which could have potentially toxic biologic effects, leading to increased blood urea nitrogen subsequently impacting kidney function $[41,42]$.

Previous studies have suggested that drinking water quality and contamination may be associated with CKDu [43-45]. Prior studies have identified cases and controls on the basis of groundwater source and found much larger odds of disease in males who drank water from shallow wells, compared to males who drank from natural springs (OR $5.4895 \% \mathrm{Cl} 3.46-8.66)$ [46, 47]. Similar findings were found for women drinking from shallow wells (OR $4.4095 \% \mathrm{Cl} 2.23-8.68)$ [46]. Due to the broad application of pesticides in all aspects of farming, potentially nephrotoxic pesticide agents contaminating the drinking water cannot be ruled out. Our findings differ somewhat from these prior studies in the minor difference between $89 \%$ (controls) and $93 \%$ (cases) reported source of drinking water as a dug well. We however, were not able to compare other sources of drinking water with high confidence and statistical power.

Dug wells are traditional wells often lined with clay brick and may be covered to prevent animals from entering. There were few participants who received water via a tap line, rainwater collectors, or methods other than a dug well. As such, our ability to evaluate drinking water source as a risk factor was limited. In addition, the number of years that participants used different types of drinking water was inconsistently recorded. Treatment of drinking water was found to be a significant risk factor for CKDu. Treatment of water included boiling water $(n=41)$, filtering water $(n=59)$, and traditional methods $(n=19)$. The most common traditional practice for water treatment was the introduction of Strychnos potatorum seeds (Sinhalese - ingini seeds) into the water source, as is customary in Sri Lanka and India [48]. One possible risk for developing CKDu related to treating drinking water could be the boiling $(n=41)$ of water in aluminum vessels [49]. Information regarding the type of cookware used with relation to boiling water was not collected.

Our study found novel risk factors for CKDu in the study region. Results regarding the potential mechanisms of association with CKDu for chewing betel, treatment of drinking water, and having pets or pests are inconclusive. For instance, dogs in Sri Lanka are often community pets and as such, ownership 
can be difficult to ascertain, although $43 \%$ of study participants reported having a pet dog. Additionally, dogs may serve as reservoirs of infectious disease that may lead to renal damage in humans. For example, outbreaks of leptospirosis have been reported during the monsoon season in some CKDu endemic regions [50,51]. Leptospirosis causes acute kidney failure in dogs, with high mortality rates among those that are untreated or without access to dialysis. Consequently, dogs may potentially shed Leptospira spirochetes in their urine. Owners or community individuals may be thus exposed, potentially clearing the infection but suffering renal damage that could later lead to developing CKDu [52]. Current Ministry of Health CKDu diagnosis criteria do not include serology or polymerase chain reaction (PCR) tests for ruling out leptospirosis; patients are asked only to self-report previous history of leptospirosis. As leptospirosis diagnostics continue to improve, future research should consider specimen collection for laboratory confirmation [53-55].

Mammalian pests in households may also be carriers of infectious disease that leads to increased susceptibility to CKDu. There is an emerging hypothesis that Hanta virus could be the possible causative agent for CKDu in Sri Lanka's dry zone [26,56]. Humans infected with Hanta virus show clinical signs similar to those of Leptospirosis, and Hanta virus infection in humans was first described in Sri Lanka in the mid-eighties [57]. Rodents act as the reservoir host for Hanta virus and Leptospirosis. Therefore, our study may provide further evidence for the association between infected rodents and prevalence of CKDu in Sri Lanka. Further research should evaluate the incidence of Hanta virus and Leptospirosis in rodents, pets, livestock, and people in CKDu-endemic regions in Sri Lanka.

To identify other disease risks that might be due to close contact with domestic animals or wildlife, data was collected concerning participant observations of illness among domestic animals in the community. There were very few reported, including three observations of ill cattle $(2.7 \%)$, one goat $(0.9 \%)$, and one chicken $(0.9 \%)$ in the month prior to the survey interview. It is possible that the lifespan of dogs and livestock in the community is short due to environmental hazards (disease, trauma, etc.) and animals go missing or die before disease can be detected or transmitted to humans.

Chewing betel was another novel risk factor for CKDu in our study. This practice is quite common among Sri Lankans, and our study found that chewing betel was more common among those reporting farming as an occupation (60\%) than other occupations (40\%). There is evidence that betel preparations include stimulant properties similar to nicotine, and chewing it routinely can lead to enamel erosion and oral cancer [58-60]. The betel preparation commonly chewed in Sri Lanka is comprised of betel, areca nut, tobacco, and lime. However, betel recipes among farmers in Sri Lanka's dry zone may contain differing substances compared to preparations in the remainder of the country, which could be associated with CKDu [58, 61, 62]. Individuals that mix and distribute pesticides may be at greater risk, as betel is inserted in the mouth and may be done in the field where hand washing is not possible. In addition, there is evidence that chewing betel increases exposure to arsenic and cadmium, both of which can be nephrotoxic [63]. 
Additionally, at our sample size $(\mathrm{n}=110)$, we do not have the power to detect small differences in effect measure or to generalize to populations outside our study region. Finally, although survey questions were detailed in nature, the question interpretation by the study participant may have varied, leading to inaccurate answers. Due to the condensed nature of the survey timeline, with multiple interviews occurring at one time, investigators could not oversee each individual interview. As such, details pertaining to the number of years when specific pesticides or water sources were used were sometimes incomplete.

This case-control study design was useful for having comparable populations with and without the disease in order to efficiently evaluate past risk factors associated with disease status. In the future, a cohort study would be a useful design to evaluate exposure data, exposure timelines, and incidence rates for $\mathrm{CKDu}$, and we recommend that future studies of CKDu in Sri Lanka be cohort-based, despite the longer follow-up period and greater expense. In addition, a nationwide, coordinated CKDu research consortium spanning all major research institutions would make CKDu research more efficient by standardizing study design and methodologies. This would allow more accurate conclusions to be drawn from studies with clear and consistent case/control definitions and study locations.

While our survey was comprehensive, our study had several limitations, primarily relating to case definition, disease progression, and study design characteristics. Temporal bias might have been introduced since the exact date of CKDu diagnosis was not collected however, the impact of bias on alcohol consumption is believed to be minimal due to a non-significant difference in the mean years since first drink $(t=-1.89)$ and frequency of alcohol consumption $(t=-0.49)$. Furthermore, there was not a significant difference in the number of years farming among those reporting a farming occupation (Fisher's exact $=0.07$ ) between cases and control.

The appearance and progression of CKDu can involve non-specific symptoms, making the disease challenging to diagnose in the early, pre-clinical stages limiting the population of cases in this study to those that were in advanced stages of the disease. Studies suggest using more sensitive methods for detecting early $\mathrm{CKDu}$, with measurement of microalbuminuria and functional markers such as Cyst $\mathrm{C}$, creatinine or tubular proteins like RBP4, NGAL or KIM would be beneficial in capturing a greater number of early-stage CKDu cases so that exposures can be better assessed and treatment initiated earlier [64-66].

The lack of association between herbicide and CKDu outcome in the adjusted model indicates either that herbicide alone is not responsible for CKDu, or that sufficient detail regarding herbicide use was not captured in the survey. For example, the volume and length of use of pesticides was difficult to assess in an interview setting compared to a household visit, where farmers could reference pesticide receipts or other family members for details they could not recall. More detailed responses regarding usage may have resulted in a difference between cases and controls, which could not be evaluated in this study.

At present, the use of the albumin-creatinine ratio or persistent proteinuria as an initial screening tool is only sensitive at detecting advanced-stage prevalent CKDu cases. This could cause misclassification of 
the disease outcome if the diagnostic test sensitivity is not high enough to differentiate between earlystage CKDu patients and controls.

\section{Conclusion}

In conclusion, this pilot case-control study showed that chewing betel, reporting of in-home pets and pests, treating drinking water, and age were significantly associated with CKDu. These cultural and environmental factors are likely part of a multi-factorial etiology that is challenging to unravel, and that may take years to understand whether preventive measures are effective. Future studies should be cohort in design and focus on further exploring the identified risk factors and their epidemiologic relationships to $\mathrm{CKDu}$, as well as possible interventions to attenuate the incidence of CKDu in Sri Lanka. Potential interventions to be considered based on these findings might include safe home pest control options, testing and treatment for leptospirosis among community dogs, routine chronic kidney disease screening among those in CKDu endemic areas, and education focused on hand hygiene in the field. These findings should be considered as research regarding CKDu in other endemic regions continues.

\section{Declarations}

Ethics approval and consent to participate

The study was approved by the University of California, Davis, Institutional Review Board (\#762486-2). All participants voluntarily provided written consent prior to questionnaire administration in their preferred language (Sinhala or Tamil).

Consent for publication

No personal, identifiable information is depicted nor represented.

\section{Availability of data and material}

Full questionnaire made available in additional file 1.

Competing interests

There are no competing nor conflicts of interest to report.

Funding 
Funding for this research was made possible through a research PASS grant from the Blum Center for Developing Economies at UC Davis, and a summer research fellowship award from the University of California Global Health Institute.

Author's contributions

All authors listed in this manuscript meet the International Committee of Journal Editors criteria for authorship.

\section{Acknowledgements}

Data collection for this study was made possible through the support provided by the Centre for Research, Education, and Training on Kidney Diseases (CERTkID), namely by the late Mr. Ranjith Mulleriya. Twelve graduate students of University of Peradeniya contributed to the study by interviewing the cases and controls. David Bunn, Ph.D. and Michael Wilkes, M.D. contributed to the researchers' understanding of the cultural role of alcohol and pesticide use.

\section{References}

1. Wang H, Naghavi M, Allen C, Barber RM, Bhutta ZA, Carter A, Casey DC, Charlson FJ, Chen AZ, Coates $\mathrm{MM}$ et al: Global, regional, and national life expectancy, all-cause mortality, and cause-specific mortality for 249 causes of death, 1980-2015: a systematic analysis for the Global Burden of Disease Study 2015. The Lancet 2016, 388(10053):1459-1544.

2. Athuraliya TN, Abeysekera DT, Amerasinghe PH, Kumarasiri PV, Dissanayake V: Prevalence of chronic kidney disease in two tertiary care hospitals: high proportion of cases with uncertain aetiology. Ceylon Med J 2009, 54(1):23-25.

3. Jha V, Garcia-Garcia G, Iseki K, Li Z, Naicker S, Plattner B, Saran R, Wang AY, Yang CW: Chronic kidney disease: global dimension and perspectives. Lancet 2013, 382(9888):260-272.

4. Lunyera J, Mohottige D, Von Isenburg M, Jeuland M, Patel UD, Stanifer JW: CKD of Uncertain Etiology: A Systematic Review. Clin J Am Soc Nephrol 2016, 11(3):379-385.

5. Couser WG, Remuzzi G, Mendis S, Tonelli M: The contribution of chronic kidney disease to the global burden of major noncommunicable diseases. Kidney Int 2011, 80(12):1258-1270.

6. Chandrajith R, Nanayakkara S, Itai K, Aturaliya TN, Dissanayake CB, Abeysekera T, Harada K, Watanabe T, Koizumi A: Chronic kidney diseases of uncertain etiology (CKDue) in Sri Lanka: geographic distribution and environmental implications. Environ Geochem Health 2011, 33(3):267278. 
7. Wanigasuriya K: Update on uncertain etiology of chronic kidney disease in Sri Lanka's north-central dry zone. MEDICC Rev 2014, 16(2):61-65.

8. Elledge MF, Redmon JH, Levine KE, Wickremasinghe RJ, Wanigasariya KP, Peiris-John RJ: Chronic Kidney Disease of Unknown Etiology in Sri Lanka: Quest for Understanding and Global Implications. RTI Press 2014.

9. Peraza S, Wesseling C, Aragon A, Leiva R, Garcia-Trabanino RA, Torres C, Jakobsson K, Elinder CG, Hogstedt C: Decreased kidney function among agricultural workers in El Salvador. Am J Kidney Dis 2012, 59(4):531-540.

10. Torres C, Aragon A, Gonzalez M, Lopez I, Jakobsson K, Elinder CG, Lundberg I, Wesseling C: Decreased kidney function of unknown cause in Nicaragua: a community-based survey. Am J Kidney Dis 2010, 55(3):485-496.

11. Statistics SLDoCa: Sri Lanka national census data 2012 for each province. In. Edited by Statistics Ca; 2012.

12. Rajapakse S, Shivanthan MC, Selvarajah M: Chronic kidney disease of unknown etiology in Sri Lanka. Int J Occup Environ Health 2016:1-6.

13. Lanka DoCaSS: Census of Population and Housing Sri Lanka 2012. In.: Department of Census and Statistics Sri Lanka.

14. Chaker L, Falla A, van der Lee SJ, Muka T, Imo D, Jaspers L, Colpani V, Mendis S, Chowdhury R, Bramer WM et al: The global impact of non-communicable diseases on macro-economic productivity: a systematic review. European Journal of Epidemiology 2015, 30(5):357-395.

15. Helantera I, Haapio M, Koskinen P, Gronhagen-Riska C, Finne P: Employment of patients receiving maintenance dialysis and after kidney transplant: a cross-sectional study from Finland. Am J Kidney Dis 2012, 59(5):700-706.

16. Klarenbach S, Stafinski T, Longobardi T, Jacobs P: The effect of renal insufficiency on workforce participation in the United States: an analysis using National Health and Nutrition Examination Survey III data. Am J Kidney Dis 2002, 40(6):1132-1137.

17. Levine KE, Redmon JH, Elledge MF, Wanigasuriya KP, Smith K, Munoz B, Waduge VA, Periris-John RJ, Sathiakumar N, Harrington JM et al: Quest to identify geochemical risk factors associated with chronic kidney disease of unknown etiology (CKDu) in an endemic region of Sri Lanka-a multimedia laboratory analysis of biological, food, and environmental samples. Environ Monit Assess 2015, 188(10):548.

18. Samsel A, Seneff S: Glyphosate, pathways to modern diseases II: Celiac sprue and gluten intolerance. Interdiscip Toxicol 2013, 6(4):159-184.

19. Wimalawansa SA, Wimalawansa SJ: Environmentally induced, occupational diseases with emphasis on chronic kidney disease of multifactorial origin affecting tropical countries. Ann Occup Environ Med 2016, 28:33.

20. Wimalawansa SJ: The role of ions, heavy metals, fluoride, and agrochemicals: critical evaluation of potential aetiological factors of chronic kidney disease of multifactorial origin (CKDmfo/CKDu) and 
recommendations for its eradication. Environ Geochem Health 2016, 38(3):639-678.

21. Bandara JMRS, Senevirathna DMAN, Dasanayake DMRSB, Herath V, Bandara JMRP, Abeysekara T, Rajapaksha $\mathrm{KH}$ : Chronic renal failure among farm families in cascade irrigation systems in Sri Lanka associated with elevated dietary cadmium levels in rice and freshwater fish (Tilapia). Environmental Geochemistry and Health 2008, 30(5):465-478.

22. Bandara JMRS, Wijewardena HVP, Liyanege J, Upul MA, Bandara JMUA: Chronic renal failure in Sri Lanka caused by elevated dietary cadmium: Trojan horse of the green revolution. Toxicology Letters 2010, 198(1):33-39.

23. Jayasumana C, Gunatilake S, Siribaddana S: Simultaneous exposure to multiple heavy metals and glyphosate may contribute to Sri Lankan agricultural nephropathy. BMC Nephro/ 2015, 16:103.

24. Wasana HM, Aluthpatabendi D, Kularatne WM, Wijekoon P, Weerasooriya R, Bandara J: Drinking water quality and chronic kidney disease of unknown etiology (CKDu): synergic effects of fluoride, cadmium and hardness of water. Environ Geochem Health 2016, 38(1):157-168.

25. Ileperuma OA, Dharmagunawardhane HA, Herath KPRP: Dissolution of aluminium from sub-standard utensils under high fluoride stress: a possible risk factor for chronic renal failure in the North-Central Province. J Natl Sci Found Sri 2009, 37(3):219-222.

26. Gamage CD, Sarathkumara YD: Chronic kidney disease of uncertain etiology in Sri Lanka: Are leptospirosis and Hantaviral infection likely causes? Med Hypotheses 2016, 91:16-19.

27. Brand RM, Jendrzejewski JL, Charron AR: Potential mechanisms by which a single drink of alcohol can increase transdermal absorption of topically applied chemicals. Toxicology 2007, 235(3):141149.

28. Brand RM, McMahon L, Jendrzejewski JL, Charron AR: Transdermal absorption of the herbicide 2,4dichlorophenoxyacetic acid is enhanced by both ethanol consumption and sunscreen application. Food and Chemical Toxicology 2007, 45(1):93-97.

29. Peiris-John RJ, Wanigasuriya JK, Wickremasinghe AR, Dissanayake WP, Hittarage A: Exposure to acetylcholinesterase-inhibiting pesticides and chronic renal failure. Ceylon Med J 2006, 51(1):42-43.

30. Valcke M, Levasseur ME, Soares da Silva A, Wesseling C: Pesticide exposures and chronic kidney disease of unknown etiology: an epidemiologic review. Environ Health 2017, 16(1):49.

31. Wanigasuriya KP, Peiris-John RJ, Wickremasinghe R, Hittarage A: Chronic renal failure in North Central Province of Sri Lanka: an environmentally induced disease. Transactions of the Royal Society of Tropical Medicine and Hygiene 2007, 101(10):1013-1017.

32. Epitools Epidemiological Calculators

33. Somatunga LC, Ratnayake LR, Wijesinghe WMDNK, Yapa YMMM, Cooray MPNS: National alcohol use prevalence survey in Sri Lanka. Journal of the Postgraduate Institute of Medicine 20114:1-12.

34. Šćiban $M$, Klašnja $M$, Antov $M$, Škrbić B: Removal of water turbidity by natural coagulants obtained from chestnut and acorn. Bioresource Technology 2009, 100(24):6639-6643. 
35. Nanayakkara S, Senevirathna ST, Abeysekera T, Chandrajith R, Ratnatunga N, Gunarathne ED, Yan J, Hitomi T, Muso E, Komiya T et al: An integrative study of the genetic, social and environmental determinants of chronic kidney disease characterized by tubulointerstitial damages in the North Central Region of Sri Lanka. J Occup Health 2014, 56(1):28-38.

36. Weaver VM, Fadrowski JJ, Jaar BG: Global dimensions of chronic kidney disease of unknown etiology (CKDu): a modern era environmental and/or occupational nephropathy? BMC Nephro/ 2015, 16:145.

37. Whiting DR, Guariguata L, Weil C, Shaw J: IDF diabetes atlas: global estimates of the prevalence of diabetes for 2011 and 2030. Diabetes Res Clin Pract 2011, 94(3):311-321.

38. Neumann J, Ligtenberg G, Klein, II, Koomans HA, Blankestijn PJ: Sympathetic hyperactivity in chronic kidney disease: pathogenesis, clinical relevance, and treatment. Kidney Int 2004, 65(5):1568-1576.

39. Hall JE: The kidney, hypertension, and obesity. Hypertension 2003, 41(3 Pt 2):625-633.

40. Anderson AH, Yang W, Townsend RR, Pan Q, Chertow GM, Kusek JW, Charleston J, He J, Kallem R, Lash JP et al: Time-updated systolic blood pressure and the progression of chronic kidney disease: a cohort study. Ann Intern Med 2015, 162(4):258-265.

41. Van Vleet TR, Schnellmann RG: Toxic nephropathy: environmental chemicals. Seminars in Nephrology 2003, 23(5):500-508.

42. Lock EA: Mechanism of Nephrotoxic Action Due to Organohalogenated Compounds. Toxicology Letters 1989, 46(1-3):93-106.

43. Chandrajith R, Dissanayake CB, Ariyarathna T, Herath HM, Padmasiri JP: Dose-dependent Na and Ca in fluoride-rich drinking water-another major cause of chronic renal failure in tropical arid regions. $S C i$ Total Environ 2011, 409(4):671-675.

44. Jayasumana C, Gunatilake S, Senanayake P: Glyphosate, hard water and nephrotoxic metals: are they the culprits behind the epidemic of chronic kidney disease of unknown etiology in Sri Lanka? Int J Environ Res Public Health 2014, 11(2):2125-2147.

45. Jayasumana C, Paranagama P, Agampodi S, Wijewardane C, Gunatilake S, Siribaddana S: Drinking well water and occupational exposure to Herbicides is associated with chronic kidney disease, in Padavi-Sripura, Sri Lanka. Environ Health-Glob 2015, 14(6).

46. Jayasekara KB, Dissanayake DM, Sivakanesan R, Ranasinghe A, Karunarathna RH, Priyantha Kumara GW: Epidemiology of chronic kidney disease, with special emphasis on chronic kidney disease of uncertain etiology, in the north central region of Sri Lanka. J Epidemio/ 2015, 25(4):275280.

47. Rango $T$, Jeuland $M$, Manthrithilake $H$, McCornick $P$ : Nephrotoxic contaminants in drinking water and urine, and chronic kidney disease in rural Sri Lanka. Science of the Total Environment 2015, 518519:574-585.

48. Adinolfi M, Corsaro MM, Lanzetta R, Parrilli M, Folkard G, Grant W, Sutherland J: Composition of the coagulant polysaccharide fraction from Strychnos potatorum seeds. Carbohydr Res 1994, 263(1):103-110. 
49. Gitelman H: Aluminum in Health A Critical Review: Marcel Dekker; 1989.

50. Agampodi SB, Dahanayaka NJ, Bandaranayaka AK, Perera M, Priyankara S, Weerawansa P, Matthias MA, Vinetz JM: Regional differences of leptospirosis in Sri Lanka: observations from a floodassociated outbreak in 2011. PLoS Negl Trop Dis 2014, 8(1):e2626.

51. Rojas P, Monahan AM, Schuller S, Miller IS, Markey BK, Nally JE: Detection and quantification of leptospires in urine of dogs: a maintenance host for the zoonotic disease leptospirosis. European Journal of Clinical Microbiology \& Infectious Diseases 2010, 29(10):1305-1309.

52. Daher EDF, Abreu KLSd, Junior GBdS: Leptospirosis-associated acute kidney injury. Jornal Brasileiro de Nefrologia 2010, 32(4):400-407.

53. Guerra MA: Leptospirosis: public health perspectives. Biologicals 2013, 41(5):295-297.

54. Musso D, La Scola B: Laboratory diagnosis of leptospirosis: a challenge. J Microbiol Immunol Infect 2013, 46(4):245-252.

55. Picardeau M, Bertherat E, Jancloes M, Skouloudis AN, Durski K, Hartskeerl RA: Rapid tests for diagnosis of leptospirosis: current tools and emerging technologies. Diagn Microbiol Infect Dis 2014, 78(1):1-8.

56. Gamage CD, Yoshimatsu K, Sarathkumara YD, Kulendiran T, Nanayakkara N, Arikawa J: Serological evidence of hantavirus infection in Girandurukotte, an area endemic for chronic kidney disease of unknown aetiology (CKDu) in Sri Lanka. Int J Infect Dis 2017, 57:77-78.

57. Vitarana S: Feasibility of biological control of the low-country live wood termite (Glyptotermes dilatatus) of tea (Camellia sinensis) in Sri Lanka. In: Proceedings of the regional tea conference Colombo, Sri Lanka: 1988; 1988: 99-112.

58. Gupta PC, Ray CS: Epidemiology of betel quid usage. Annals of the Academy of Medicine, Singapore 2004, 33(4 Suppl):31-36.

59. Amarasinghe HK, Usgodaarachchi US, Johnson NW, Lalloo R, Warnakulasuriya S: Betel-quid chewing with or without tobacco is a major risk factor for oral potentially malignant disorders in Sri Lanka: a case-control study. Oral Oncol 2010, 46(4):297-301.

60. Gupta PC, Warnakulasuriya S: Global epidemiology of areca nut usage. Addict Biol 2002, 7(1):77-83.

61. Ariyawardana A, Athukorala AD, Arulanandam A: Effect of betel chewing, tobacco smoking and alcohol consumption on oral submucous fibrosis: a case-control study in Sri Lanka. J Oral Pathol Med 2006, 35(4):197-201.

62. Jacob BJ, Straif K, Thomas G, Ramadas K, Mathew B, Zhang ZF, Sankaranarayanan R, Hashibe M: Betel quid without tobacco as a risk factor for oral precancers. Oral Oncol 2004, 40(7):697-704.

63. Al-Rmalli SW, Jenkins RO, Haris PI: Betel quid chewing elevates human exposure to arsenic, cadmium and lead. Journal of Hazardous Materials 2011, 190(1-3):69-74.

64. Lopez-Marin L, Chavez Y, Garcia XA, Flores WM, Garcia YM, Herrera R, Almaguer M, Orantes CM, Calero D, Bayarre HD et al: Histopathology of chronic kidney disease of unknown etiology in Salvadoran agricultural communities. MEDICC Rev 2014, 16(2):49-54. 
65. Redmon JH, Elledge MF, Womack DS, Wickremashinghe R, Wanigasuriya KP, Peiris-John RJ, Lunyera J, Smith K, Raymer JH, Levine KE: Additional perspectives on chronic kidney disease of unknown aetiology (CKDu) in Sri Lanka-lessons learned from the WHO CKDu population prevalence study. BMC Nephrol 2014, 15:125.

66. Ratnayake S, Badurdeen Z, Nanayakkara N, Abeysekara T, Ratnatunga N, Kumarasiri R: Screening for chronic kidney disease of uncertain aetiology in Sri Lanka: usability of surrogate biomarkers over dipstick proteinuria. BMC Nephrol 2017, 18(1):199.

\section{Appendix}

Additional File 1

Table S1. Characteristics of Population Surveyed 
$(\mathrm{N}=54) \quad(\mathrm{N}=56)$

n (\%)

n (\%)

Respondent Demographics and Health

\begin{tabular}{|c|c|c|c|c|}
\hline Gender & Male & $26(49)$ & $40(71)$ & 0.02 \\
\hline Age, mean (SD) & & $49.5(11.70)$ & $57.5(9.59)$ & $<0.01$ \\
\hline Most Villagers Related ${ }^{\ddagger}$ & Yes & $23(43)$ & $33(59)$ & 0.09 \\
\hline \multirow[t]{5}{*}{ Education Level } & No formal schooling & $5(9)$ & $9(16)$ & \multirow[t]{5}{*}{0.04} \\
\hline & Primary & $14(26)$ & $27(49)$ & \\
\hline & Middle & $15(28)$ & $11(20)$ & \\
\hline & Secondary & $16(30)$ & $7(13)$ & \\
\hline & $>$ Secondary & $3(6)$ & $1(2)$ & \\
\hline \multirow[t]{2}{*}{ Income during Maha season } & $<25,000$ LKR & $6(12)$ & $12(22)$ & \multirow[t]{5}{*}{0.14} \\
\hline & $\geq 25,000$ to $<50,000$ LKR & $10(21)$ & $14(26)$ & \\
\hline \multirow{3}{*}{ (from Sep-March) } & $\geq 50,000$ to $<100,000$ LKR & $14(29)$ & $17(31)$ & \\
\hline & $\geq 100,000$ LKR & $15(31)$ & $6(11)$ & \\
\hline & Unknown/declined & $3(6)$ & $5(9)$ & \\
\hline \multirow[t]{2}{*}{ Income during Yala season } & $<25,000$ LKR & $9(23)$ & $17(40)$ & \multirow[t]{5}{*}{0.08} \\
\hline & $\geq 25,000$ to $<50,000$ LKR & $10(26)$ & $14(33)$ & \\
\hline \multirow{3}{*}{ (from May-Aug) } & $\geq 50,000$ to $<100,000$ LKR & $8(21)$ & $7(17)$ & \\
\hline & $\geq 100,000$ LKR & $10(26)$ & $2(5)$ & \\
\hline & Unknown/declined & $2(5)$ & $2(5)$ & \\
\hline \multirow[t]{3}{*}{ Medical care provider } & Private & $5(9)$ & $0(0)$ & \multirow[t]{3}{*}{0.01} \\
\hline & Government & $29(54)$ & $42(76)$ & \\
\hline & Other & $20(37)$ & $13(24)$ & \\
\hline \multirow[t]{3}{*}{ Annual medical expenses } & No Expense Declared & $5(9)$ & $6(11)$ & \multirow[t]{3}{*}{0.06} \\
\hline & $<1,000$ LKR & $17(31)$ & $6(11)$ & \\
\hline & $\geq 1,000$ to $<10,000$ LKR & $22(41)$ & $29(52)$ & \\
\hline
\end{tabular}




\begin{tabular}{|c|c|c|c|c|}
\hline & $\geq 10,000$ LKR & $10(19)$ & $15(27)$ & \\
\hline \multirow[t]{4}{*}{ Average annual clinic visits } & $1-6$ times & $22(43)$ & $3(5)$ & \multirow[t]{4}{*}{$<0.01$} \\
\hline & 7-12 times & $14(27)$ & $17(30)$ & \\
\hline & 13-18 times & $9(18)$ & $19(34)$ & \\
\hline & $>18$ times & $6(12)$ & $17(30)$ & \\
\hline Chew betel & Yes & $22(41)$ & $40(71)$ & $<0.01$ \\
\hline Smoke tobacco/cannabis & Yes & $14(26)$ & $19(34)$ & 0.36 \\
\hline \multicolumn{5}{|c|}{ Agricultural Information } \\
\hline Occupation farming & Yes & $36(72)$ & $51(94)$ & $<0.01$ \\
\hline Use insecticide & Yes & $42(78)$ & $44(79)$ & 0.92 \\
\hline Use fungicide & Yes & $21(44)$ & $29(55)$ & 0.27 \\
\hline Use pesticide in home & Yes & $9(20)$ & $12(22)$ & 0.87 \\
\hline Use herbicide & Yes & $41(76)$ & $51(91)$ & 0.03 \\
\hline \multirow[t]{4}{*}{ Agro-mechanization } & None & $10(21)$ & $9(17)$ & \multirow[t]{4}{*}{0.76} \\
\hline & Some & $10(21)$ & $11(21)$ & \\
\hline & Much & $11(23)$ & $17(33)$ & \\
\hline & All & $16(34)$ & $15(29)$ & \\
\hline \multirow[t]{3}{*}{ Farm type } & Highland & $2(4)$ & $5(9)$ & \multirow[t]{3}{*}{0.42} \\
\hline & Lowland & $41(85)$ & $45(85)$ & \\
\hline & Highland \& Lowland & $5(10)$ & $3(6)$ & \\
\hline Use pesticide spray PPE & Yes & $14(56)$ & $25(68)$ & 0.35 \\
\hline \multicolumn{5}{|c|}{ Alcohol Consumption } \\
\hline Consume kasippu & Yes & $13(24)$ & $18(32)$ & 0.35 \\
\hline Consume arrack & Yes & $19(35)$ & $27(48)$ & 0.17 \\
\hline Consume beer & Yes & $14(26)$ & $16(29)$ & 0.76 \\
\hline Consume other alcohol & Yes & $8(15)$ & $12(21)$ & 0.37 \\
\hline \multirow[t]{3}{*}{ Perceived alcohol problem in village } & No problem & $13(27)$ & $11(21)$ & \multirow[t]{3}{*}{0.85} \\
\hline & Minor problem & $17(35)$ & $20(38)$ & \\
\hline & Moderate problem & $10(20)$ & $9(17)$ & \\
\hline
\end{tabular}


Water and Nutrition

\begin{tabular}{l|l|c|c|c}
\hline Drink dug well water & Yes & $48(89)$ & $52(93)$ & 0.47 \\
\hline Drink rainwater & Yes & $6(11)$ & $5(9)$ & 0.70 \\
\hline Treat drinking water & Yes & $34(63)$ & $41(75)$ & 0.19 \\
\hline Meal preparation changed & Yes & $19(35)$ & $26(46)$ & 0.23 \\
\hline Micturition & 2 times/day & $6(11)$ & $6(11)$ & 0.21 \\
\cline { 3 - 5 } & 3 times/day & $5(9)$ & $11(20)$ \\
\hline & 4 times/day & $15(28)$ & $8(14)$ \\
\hline
\end{tabular}

\section{Animal Exposure/Health, and Sanitation}

\begin{tabular}{l|l|c|c|c}
\hline Own a pet & Yes & $28(52)$ & $40(71)$ & 0.04 \\
\hline Keep livestock & Yes & $17(31)$ & $19(34)$ & 0.78 \\
\hline Observed ill livestock & Yes & $2(4)$ & $3(5)$ & 0.68 \\
\hline Livestock enter bathing water & No & $22(41)$ & $34(61)$ & 0.05 \\
\cline { 2 - 5 } & Yes & $13(24)$ & $13(23)$ & \\
\cline { 2 - 5 } & Unknown & $19(35)$ & $9(16)$ & \\
\hline Report pests in home & Yes & $36(68)$ & $46(84)$ & 0.06 \\
\hline & Yes & $26(49)$ & $32(58)$ & 0.34 \\
\hline Family member CKDu (+) & Yes & $13(24)$ & $2(4)$ & $<0.01$ \\
\hline Ever diagnosed with diabetes & Yes & $12(22)$ & $29(52)$ & $<0.01$ \\
\hline Ever diagnosed with hypertension & Yes & $23(43)$ & $33(59)$ & 0.09 \\
\hline Most villagers related & & & & \\
\hline
\end{tabular}

